\title{
ARTICLE OPEN \\ Predictors of poor-quality spirometry in two cohorts of older adults in Russia and Belgium: a cross-sectional study
}

\author{
Eralda Turkeshi ${ }^{1,4}$, Dmitry Zelenukha ${ }^{2,4}$, Bert Vaes ${ }^{1,3}$, Elena Andreeva ${ }^{1}$, Elena Frolova ${ }^{2}$ and Jean-Marie Degryse ${ }^{1,3}$
}

BACKGROUND: Spirometry is an important test for the diagnosis of respiratory diseases, yet it is underused especially in older adults. Several predictors of good-quality spirometry in this age group have been reported, based mainly on in/outpatients of geriatric and/or respiratory units.

AIMS: This study aims to assess predictors of poor-quality spirometry in community-dwelling older adults from two primary care cohorts in Russia and Belgium.

METHODS: Spirograms from two population-based cohort studies in Russia (CRYSTAL) and Belgium (BELFRAIL) were assessed in accordance with the American Thoracic Society/European Respiratory Society (ATS/ERS) acceptability and repeatability criteria and grouped into good and poor quality. Multivariable analysis assessed the association of poor-quality spirometry with sociodemographics, functional dependency, physical and mental functioning and co-morbidities.

RESULTS: In all, $43.3 \%$ of the 522 BELFRAIL participants $(84.71 \pm 3.67$ years old) and $57.7 \%$ of the 605 CRYSTAL participants (75.11 \pm 5.97 years old) achieved all ATS/ERS acceptability and repeatability criteria. In both cohorts, those with poor-quality spirometry had lower cognitive function (mini-mental state examination (MMSE) $\leqslant 24$ ). After adjustment in multivariable analysis, MMSE $\leqslant 24$ had an odds ratio for poor-quality spirometry of $1.33(95 \% \mathrm{Cl}=0.78-2.28)$ in the BELFRAIL and $1.30(95 \% \mathrm{Cl}=0.88-1.91)$ in the CRYSTAL cohort.

CONCLUSIONS: In community-dwelling older adults, including those over 80 years old, impaired cognition measured by the MMSE may not be an independent predictor of poor-quality spirometry. Further research is needed in this area, and spirometry should be used more often in older adults in primary care.

npj Primary Care Respiratory Medicine (2015) 25, 15048; doi:10.1038/npjpcrm.2015.48; published online 23 July 2015

\section{INTRODUCTION}

Chronic obstructive pulmonary disease (COPD) is becoming a major cause of morbidity and mortality, especially in light of the worldwide trend of population ageing. ${ }^{1}$ Spirometry is essential for the diagnosis, assessment of severity and follow-up of COPD and asthma. ${ }^{2,3}$ Besides this, spirometry parameters such as forced expiratory volume in $1 \mathrm{~s}\left(\mathrm{FEV}_{1}\right)$ have been found to be predictors of adverse health outcomes such as all-cause mortality, disability and frailty in the older adults. ${ }^{4-8}$ Yet, there is still underuse of spirometry for diagnosing respiratory problems, especially in older adults, even though it has become widely available in primary care and hand-held office spirometry is reliable. ${ }^{9-12}$

The quality of spirometry is very important for its interpretation, and standardisation guidelines are available on acceptability and repeatability criteria. $^{13}$ These criteria require at least three acceptable forced vital capacity manoeuvres, but in older adults five to eight are needed to meet the quality criteria, and depending on the setting, the majority of older adults meet them. ${ }^{14}$ Several factors that predict good quality of spirometry in older adults have been identified, such as a skilled operator, female sex, younger age (65-80), better education, cognitive function, stamina and mood, as well as the absence of obesity/ malnutrition. ${ }^{14}$

As previous studies on the quality of spirometry in older adults have mainly included older adults either as in/outpatients of geriatric and/or respiratory units, ${ }^{15-20}$ the aim of this paper is to assess which of the previously reported factors predict poorquality spirometry in community-dwelling older adults from two different primary care cohorts in Russia and Belgium.

\section{MATERIALS AND METHODS}

\section{Study designs and populations}

The BELFRAIL study is a prospective, observational, population-based cohort study of people $\geqslant 80$ years old living in Belgium aiming to improve the understanding of the epidemiology and pathophysiology of chronic diseases in this age group. ${ }^{21}$ The CRYSTAL study is a prospective cohort study of community-dwelling individuals aged 65 years and older living in the Kolpino district of St Petersburg, Russia aiming to provide a picture of the health and functional status of community-dwelling older adults in this area. $^{22}$ The studies' protocols and sampling methods have already been described in detail elsewhere. ${ }^{21,22}$ Briefly, between November 2008 and September 2009, in 29 general practitioner centres in Belgium, 567 community-dwelling individuals $\geqslant 80$ years old were recruited in the BELFRAIL cohort, excluding only those with dementia (known previous mini-mental state examination (MMSE) score $<15$ ) or those in palliative or emergency care. In the primary care clinic of Kolping in St Petersburg, Russia between March and December 2009, 611 community-dwelling adults $>65$ years old were recruited in the CRYSTAL study. In both the studies, at baseline, the participants' general practitioners recorded sociodemographic data and medical history. An extensive standardised

\footnotetext{
${ }^{1}$ Institute of Health and Society, Université Catholique de Louvain, Brussels, Belgium; ${ }^{2}$ Department of Family Medicine, North-Western State Medical University, St Petersburg, Russia and ${ }^{3}$ Department of Public Health and Primary Care, Katholieke Universiteit Leuven, Leuven, Belgium.

Correspondence: E Turkeshi (eralda.turkeshi@student.uclouvain.be)

${ }^{4}$ These authors contributed equally to this work.

Received 13 November 2014; revised 17 April 2015; accepted 5 June 2015
} 
assessment by trained clinical research assistants included standardised biometric measurements, performance tests, questionnaires and technical tests including spirometry. The studies' protocols were approved by the appropriate local ethics committees, and informed consent was obtained from all the participants. ${ }^{21,22}$

\section{Spirometry}

In both studies, spirometry was performed by trained clinical research assistants (two at BELFRAIL and four at CRYSTAL study) either at the home of the participants (BELFRAIL) or at the polyclinic (CRYSTAL), using a Spirobank spirometer (MIR, Rome, Italy) that has been found to be reliable for research purposes. ${ }^{23}$ The spirometer was linked to a computer with the Winspiro Pro software that provided real-time feedback (in the clinical research assistant's language) on the flow-volume curves, as well as an automated quality analysis. Spirometry was performed according to the American Thoracic Society/European Respiratory Society (ATS/ERS) standards. ${ }^{13}$ Repeatability of the spirometry was automatically calculated by the software in accordance with the ATS/ERS criteria. ${ }^{13}$ In both studies, two independent researchers evaluated all the spirograms by the ATS/ERS criteria by reviewing the characteristics of the flow-volume curves, as well as numerical data, and classified them in the following levels: 1-all ATS/ ERS criteria are fulfilled including repeatability; 2-all ATS/ERS criteria are fulfilled except duration of expiration $>6 \mathrm{~s} ; 3$-spirograms have good starts and no cough during the first second of manoeuvre; 4-none of the ATS/ ERS criteria are fulfilled. All the participants in both the studies were grouped into those with good- (ATS 1) or poor (ATS 2-4)-quality spirometry.

\section{Physical and mental functioning}

Activities of daily living for BELFRAIL and Barthel Index of daily activities for CRYSTAL study, as well as physical performance tests (PPT) and grip strength, were used as measures of physical function. ${ }^{21,22}$

The total activities of daily living scores in the BELFRAIL study were ranked in gender-specific quintiles, and the lowest quintile was used as a proxy for activities of daily living disability. The cutoff for physical dependency in the CRYSTAL study was Barthel Index score $<95$.

The physical performance tests in both the studies consisted of measured times of walking $3 \mathrm{~m}$ and return, sitting and standing from a chair, putting on and taking off a cardigan and maintaining balance in a tandem stand. ${ }^{21,22}$ The summary physical performance tests score was ranked into quartiles with the lowest gender-specific quartile as cutoff for poor physical performance.

The cutoff for poor grip strength in the BELFRAIL study was the lowest gender-specific quartile of the best score of three attempts with the dominant hand. ${ }^{21}$ In the CRYSTAL study, the gender-specific lowest quartile of the average score of three attempts with the dominant hand was used as the cutoff for poor grip strength. ${ }^{22}$

The MMSE and the 15-item Geriatric Depression Scale (GDS-15) were used as measures of mental functioning. ${ }^{21,22}$ Participants were classified into those with normal cognitive status (25-30 points) and those with various stages of cognitive impairment (mild: 24-21; moderate: 20-10; severe: $\leqslant 9$ ). The GDS-15 score of $\geqslant 5$ was used to identify participants at risk for depression.

\section{Other variables}

In addition to age, sex and BMI (body mass index), other variables included in the statistical analysis were as follows: smoking status (never, previous or current smoker), co-morbidities (simple disease count for a list of co-morbidities), dyspnoea (modified Medical Research Council scale) and level of education (primary, secondary or higher; available only in the BELFRAIL study). ${ }^{21,22}$

\section{Statistical analysis}

Descriptive statistics were calculated for all variables, with the continuous variables presented as mean \pm s.d. or median and interquartile range, and categorical ones as numbers and frequencies. Comparison of baseline variables across the two groups of good and poor spirometry quality was tested with $t$-test for independent samples for parametric variables, MannWhitney U-test for non-parametric variables and Pearson's $X^{2}$ test for categorical variables. Multivariable logistic regression was used to estimate the association of cognitive impairment with poor spirometry quality (adjusted in three consecutive steps). Variables were first checked for multicollinearity. Statistical significance was considered at a two-tailed probability value $<0.05$. Statistical analysis was performed using SPSS 22.0 for Windows (SPSS Inc., Chicago, IL, USA).

\section{RESULTS}

The BELFRAIL cohort consisted of 567 participants aged $\geqslant 80$ years, and 522 performed spirometry during the baseline assessment. Forty-five participants either refused to have spirometry or it was not possible because of technical reasons. They had no statistically significant differences from the rest of the participants regarding baseline characteristics. The quality of spirograms was scored as ATS 1 in 226 participants (43.3\%), ATS 2 in 214 participants (41\%), ATS 3 in 61 participants (11.7\%) and ATS 4 in 21 participants (4\%).

The main baseline characteristics of the BELFRAIL study population in total and by spirometry quality are shown in Table 1. Those who achieved all the ATS/ERS spirometry criteria (good quality) were younger, more often men, previous/current smokers, with asthma/COPD, higher scores of MMSE, activities of daily living, grip strength and lower scores of GDS-15.

In multivariable analysis, only female sex, lower education level, GDS-15 score $\geqslant 5$ and lack of COPD/asthma were predictors of poor-quality spirograms (Table 2). The adjusted odds ratio of impaired cognitive impairment (MMSE $\leqslant 24)$ for poor-quality spirometry was $1.33(95 \% \mathrm{Cl}=0.78-2.28)$.

The CRYSTAL cohort consisted of 611 participants aged $\geqslant 65$ years, and 605 performed spirometry during the baseline assessment. The quality of spirometry was ATS 1 in 349 participants (57.7\%), ATS 2 in 103 participants (17\%), ATS 3 in 32 participants (5.3\%) and ATS 4 in 121 participants (20\%).

The main baseline characteristics of the CRYSTAL study population in total and by spirometry quality groups are shown in Table 3. There were statistically significant differences between those with good and poor spirometry quality only regarding MMSE score. MMSE score $\leqslant 24$ had an adjusted odds ratio of 1.30 $(95 \% \mathrm{Cl}=0.88-1.91)$ for poor-quality spirometry (Table 4$)$.

\section{DISCUSSION}

\section{Main findings}

In two cohorts of community-dwelling older adults in Belgium and Russia, even though there were more participants with MMSE $\leqslant 24$ in the group with poor-quality spirometry, in multivariable analysis impaired cognition (MMSE $\leqslant 24$ ) was not found to be an independent predictor of poor-quality spirometry. In the BELFRAIL cohort, female sex, lower level of education, GDS-15 score $\geqslant 5$ and lack of COPD/asthma diagnosis were found to be independent predictors of poor-quality spirometry.

Interpretation of findings in relation to previously published work Previous studies on factors affecting the ability of older adults (mean age of 71 to 85 years) to perform good-quality spirometry have reported success rates ranging from $20 \%$ in acute care geriatric units' patients up to $94 \%$ in community-dwelling participants, using different definitions of good-quality spirometry (either fulfilment of acceptability criteria only or both acceptability and repeatability criteria by ATS94 or ATS/ERS). ${ }^{15-18,20,24-27}$ In our two cohorts of community-dwelling older adults, $84.3 \%$ of the BELFRAIL participants and $74.7 \%$ of the CRYSTAL ones performed spirometry that fulfilled all the ATS/ERS criteria except for the duration of expiration $>6 \mathrm{~s}$ (levels ATS 1 and 2). Lack of a plateau of more than $6 \mathrm{~s}$ should not classify spirograms as not usable for analysis and interpretation of lung function. ${ }^{13,28} \mathrm{FEV}_{1} / \mathrm{FEV}_{6}$ has been found to be an appropriate substitute of $\mathrm{FEV}_{1} / \mathrm{forced}$ vital capacity, and spirometers that measure $\mathrm{FEV}_{6}$ and provide lower limit of normal ranges are available. ${ }^{14,29-33}$ The role of $\mathrm{FEV}_{1} / \mathrm{FEV}_{3}$ has been explored as well. ${ }^{18,34}$ In addition, FEV $_{1}$ as a potential risk 
Table 1. Baseline characteristics of the BELFRAIL study population in total and across the categories of spirometry quality

\begin{tabular}{|c|c|c|c|c|}
\hline \multirow[t]{2}{*}{ Characteristics } & \multicolumn{2}{|c|}{ Spirometry quality } & \multirow[t]{2}{*}{$\mathrm{P}$} & \multirow[t]{2}{*}{ Total population } \\
\hline & ATS $1(\mathrm{n}=226)$ & ATS $2-4(\mathrm{n}=296)$ & & \\
\hline Age(years), mean \pm s.d. & $84.3 \pm 3.2$ & $85.1 \pm 4.0$ & $0.01^{a}$ & $84.71 \pm 3.7$ \\
\hline Sex (men), $n(\%)$ & $105(46.5)$ & $87(29.4)$ & $<0.001^{\mathrm{b}}$ & $192(36.8)$ \\
\hline BMI $\left(\mathrm{kg} / \mathrm{m}^{2}\right)$, mean \pm s.d. & $27.3 \pm 4.7$ & $27.4 \pm 5.0$ & $0.82^{\mathrm{a}}$ & $27.3(4.9)$ \\
\hline \multicolumn{5}{|l|}{ Education level, n (\%) } \\
\hline Primary & $72(32.1)$ & $119(40.6)$ & $0.13^{\mathrm{b}}$ & $191(36.6)$ \\
\hline Secondary & $121(54)$ & $142(48.5)$ & & $263(50.4)$ \\
\hline Higher & $31(13.8)$ & $32(10.9)$ & & $63(12.1)$ \\
\hline Current/previous smoker, $n$ (\%) & $87(39.9)$ & 77 (26.9) & $0.002^{\mathrm{b}}$ & $164(31.4)$ \\
\hline COPD/asthma, $n(\%)$ & $44(20.2)$ & $27(9.4)$ & $0.001^{\mathrm{b}}$ & 71 (13.6) \\
\hline Non-respiratory co-morbidity, median (IQR) & $4(3-6.25)$ & $5(3-7)$ & $0.349^{c}$ & $5(3-7)$ \\
\hline \multicolumn{5}{|l|}{$m M R C, \mathrm{n}(\%)$} \\
\hline Grade 0 & $101(44.7)$ & $128(43.4)$ & $0.40^{\mathrm{b}}$ & $229(44)$ \\
\hline Grade 1 & $56(24.8)$ & $87(29.5)$ & & $143(27.4)$ \\
\hline Grade 2 & $30(13.3)$ & $25(8.5)$ & & 55 (10.6) \\
\hline Grade 3 & $32(14.2)$ & 46 (15.6) & & $78(15)$ \\
\hline Grade 4 & $7(3.1)$ & $9(3.1)$ & & $16(3)$ \\
\hline MMSE score, median (IQR) & $28(26-29)$ & $27(25-29)$ & $0.002^{c}$ & $28(26-29)$ \\
\hline \multicolumn{5}{|l|}{ MMSE categories, n (\%) } \\
\hline Normal $(\geqslant 25)$ & $194(85.8)$ & $227(76.7)$ & $0.010^{\mathrm{b}}$ & $421(80.7)$ \\
\hline Cognitive impairment $(\leqslant 24)$ & $32(14.2)$ & $69(23.3)$ & & $101(19.3)$ \\
\hline Mild (24-21) & $23(10.2)$ & $40(13.5)$ & $0.279^{\mathrm{b}}$ & $63(12.1)$ \\
\hline Moderate $(20-10)$ & $8(3.5)$ & $27(9.1)$ & $0.013^{b}$ & $35(6.6)$ \\
\hline Severe $(\leqslant 9)$ & $1(0.5)$ & $2(0.7)$ & $1.0^{\mathrm{b}}$ & $3(0.6)$ \\
\hline GDS-15 score, median (IQR) & $2(1-3)$ & $2.5(1-5)$ & $0.004^{c}$ & $2(1-4)$ \\
\hline \multicolumn{5}{|l|}{ GDS-15 categories } \\
\hline Normal $(<5)$ & $194(85.8)$ & $220(74.3)$ & $0.001^{b}$ & $414(79.3)$ \\
\hline At risk for depression $(\geqslant 5)$ & $32(14.2)$ & $76(25.7)$ & & $108(20.7)$ \\
\hline ADL score, median (IQR) & $26(22-29)$ & $24(20-27)$ & $0.004^{c}$ & $25(21-27)$ \\
\hline Grip strength $(\mathrm{kg})$, median (IQR) & $21.8(17.3-28.2)$ & $19.9(14.8-26.1)$ & $0.004^{c}$ & 20. (16.1-27.1) \\
\hline PPT score $(0-14)$, median (IQR) & $9(6-11)$ & $9(5-11)$ & $0.527^{c}$ & $9(5-11)$ \\
\hline $\begin{array}{l}\text { Non-respiratory co-morbidity was based on } \\
\text { osteoporosis, cancer, depression, hypertensior } \\
\text { accidents, peripheral arterial disease, decomp } \\
\text { Abbreviations: ADL, activity of daily living; } A \\
15 \text {-item Geriatric Depression Scale; IQR, interq } \\
\text { PPT, physical performance test. } \\
\text { a } P \text { based on } t \text {-test for independent samples. } \\
\text { b } P \text { based on Pearson } X^{2} \text { test. } \\
{ }^{C} P \text { based on Mann-Whitney U-test. }\end{array}$ & $\begin{array}{l}\text { se count of gen } \\
\text { ngina pectoris, my } \\
\text { t failure, valvular } \\
\text { Thoracic Society; } \\
\text { mMRC, modified }\end{array}$ & $\begin{array}{l}\text { Ioner-reported an } \\
\text { farction, cardiomyc } \\
\text { yroid dysfunction, } \\
\text { mass index; COP } \\
\text { search Council dys }\end{array}$ & $\begin{array}{l}\text { hyperlipi } \\
\text { bstructive } \\
\text { MMSE, mi }\end{array}$ & $\begin{array}{l}\text { itis, osteoarthritis } \\
\mathrm{s} \text {, cerebrovascular } \\
\text { rial fibrillation. } \\
\text { y disease; GDS-15, } \\
\text { state examination }\end{array}$ \\
\hline
\end{tabular}

Table 2. Multivariable logistic regression analysis of the association between MMSE score and poor spirometry quality in the BELFRAIL study

\begin{tabular}{|c|c|c|c|c|}
\hline Variables & Unadjusted & Model 1 & Model 2 & Model 3 \\
\hline MMSE $(\leqslant 24)$ & $1.84(1.16-2.92)^{* *}$ & $1.55(0.95-2.54)$ & $1.40(0.83-2.37)$ & $1.33(0.78-2.28)$ \\
\hline Age & & $1.05(1.00-1.11)$ & $1.05(0.99-1.11)$ & $1.06(1.00-1.12)$ \\
\hline Sex (male) & & $0.51^{* * *}(0.35-0.74)$ & $0.42 * *(0.26-0.68)$ & $0.44^{* *}(0.27-0.72)$ \\
\hline Education level (primary) & & $1.39(0.95-2.04)$ & $1.43(0.96-2.12)$ & $1.53^{*}(1.02-2.29)$ \\
\hline BMI & & & $0.99(0.95-1.03)$ & $0.98(0.94-1.03)$ \\
\hline ADL (lowest gender-specific quintile) & & & $1.04(0.61-1.78)$ & $1.27(0.73-2.23)$ \\
\hline Grip strength (lowest gender-specific quartile) & & & $0.68(0.41-1.11)$ & $0.63(0.38-1.04)$ \\
\hline PPT (lowest gender-specific quartile) & & & $1.07(0.62-1.87)$ & $1.03(0.58-1.83)$ \\
\hline GDS-15 ( $\geqslant 5)$ & & & $1.80 *(1.08-3.00)$ & $1.71 *(1.00-2.90)$ \\
\hline Non-respiratory morbidity & & & & $0.96(0.90-1.04)$ \\
\hline COPD/asthma & & & & $0.50 *(0.29-0.88)$ \\
\hline
\end{tabular}

Multimorbidity was based on simple disease count of coronary heart disease, myocardial infarction, diabetes, atrial fibrillation, peripheral arterial disease, stroke, hypertension, Parkinson's disease, arthritis or osteoarthritis, fractures and cancer.

Abbreviations: ADL, activity of daily living; BMI, body mass index; COPD, chronic obstructive pulmonary disease; GDS-15, 15-item Geriatric Depression Scale; MMSE, mini-mental state examination; PPT, physical performance test.

${ }^{*} P<0.05,{ }^{*} P<0.01,{ }^{* *} P<0.001$. 
Table 3. Baseline characteristics of the CRYSTAL study population in total and across the categories of spirometry quality

\begin{tabular}{|c|c|c|c|c|}
\hline \multirow[t]{2}{*}{ Characteristics } & \multicolumn{2}{|c|}{ Spirometry quality } & \multirow[t]{2}{*}{$P$} & \multirow[t]{2}{*}{ Total population } \\
\hline & ATS $1(\mathrm{n}=349)$ & ATS $2-4(\mathrm{n}=256)$ & & \\
\hline Age (years), mean \pm s.d. & $74.8 \pm 5.9$ & $75.4 \pm 5.9$ & $0.11^{\mathrm{a}}$ & $75.11 \pm 6.0$ \\
\hline \multicolumn{5}{|l|}{ Age group, $n$ (\%) } \\
\hline $65-79$ years old & $268(76.8)$ & $186(72.7)$ & $0.25^{\mathrm{b}}$ & $454(75)$ \\
\hline$\geqslant 80$ years old & $81(23.2)$ & $70(27.3)$ & & $151(25)$ \\
\hline Sex (male), $n(\%)$ & $104(29.8)$ & $66(25.8)$ & $0.31^{\mathrm{b}}$ & $170(28.1)$ \\
\hline BMI $\left(\mathrm{kg} / \mathrm{m}^{2}\right)$, mean \pm s.d. & $28.7 \pm 5.1$ & $28.4 \pm 4.8$ & $0.32^{\mathrm{a}}$ & $28.6 \pm 5.0$ \\
\hline Current/previous smoker, $n$ (\%) & $61(17.5)$ & $46(18)$ & $0.91^{\mathrm{b}}$ & $107(17.7)$ \\
\hline COPD/asthma, $n(\%)$ & $83(23.8)$ & $62(24.2)$ & $0.92^{\mathrm{b}}$ & $145(24)$ \\
\hline Non-respiratory co-morbidity, median (IQR) & $2(1-3)$ & $2(1-3)$ & $0.74^{c}$ & $2(1-3)$ \\
\hline \multicolumn{5}{|l|}{$m M R C, n(\%)$} \\
\hline Grade 0 & $102(29.6)$ & $72(28.6)$ & $0.21^{\mathrm{b}}$ & $174(29.1)$ \\
\hline Grade 1 & $170(49.3)$ & $113(44.8)$ & & $283(47.4)$ \\
\hline Grade 2 & $42(12.2)$ & 29 (11.5) & & 71 (11.9) \\
\hline Grade 3 & $22(6.4)$ & $24(9.5)$ & & $46(7.7)$ \\
\hline Grade 4 & $9(2.6)$ & $14(5.6)$ & & $23(3.9)$ \\
\hline MMSE score, median (IQR) & $26(24-28)$ & $26(23-28)$ & $0.02^{\mathrm{C}}$ & $26(23-28)$ \\
\hline \multicolumn{5}{|l|}{ MMSE score, $\mathrm{n}$ (\%) } \\
\hline Normal $(\geqslant 25)$ & $240(68.8)$ & $156(60.9)$ & $0.047^{b}$ & $396(65.5)$ \\
\hline Cognitive impairment $(\leqslant 24)$ & 109 (31.2) & $100(39.1)$ & & 209 (34.5) \\
\hline Mild (21-24) & $66(18.9)$ & $58(22.7)$ & $0.26^{\mathrm{b}}$ & 124 \\
\hline Moderate $(20-10)$ & 40 (11.5) & $38(14.8)$ & $0.22^{\mathrm{b}}$ & 78 \\
\hline Severe $(9)$ & $3(0.9)$ & $4(1.6)$ & $0.46^{\mathrm{b}}$ & 7 \\
\hline GDS-15 score, median (IQR) & $4(2-6.7)$ & $4(2-7)$ & $0.05^{c}$ & $4(2-7)$ \\
\hline \multicolumn{5}{|l|}{ GDS-15 score, $\mathrm{n}(\%)$} \\
\hline Normal $(<5)$ & $200(57.3)$ & $127(49.6)$ & $0.07^{\mathrm{b}}$ & $327(54)$ \\
\hline At risk for depression $(\geqslant 5)$ & $149(42.7)$ & $129(50.4)$ & & $278(46)$ \\
\hline Barthel Index score, median (IQR) & $100(95-100)$ & $93.7(95-100)$ & $0.45^{\mathrm{c}}$ & $100(95-100)$ \\
\hline \multicolumn{5}{|l|}{ Barthel Index, n (\%) } \\
\hline Independent $(\geqslant 95)$ & $263(75.4)$ & $199(77.7)$ & $0.56^{\mathrm{b}}$ & $462(76.4)$ \\
\hline Dependent $(<95)$ & $86(24.6)$ & $57(22.3)$ & & $143(23.6)$ \\
\hline Grip strength (kg), median (IQR) & $15.7(11.1-20.9)$ & $16.3(11.7-23.0)$ & $0.07^{\mathrm{c}}$ & $16.3(11.7-21.7)$ \\
\hline PPT score (0-14), median (IQR) & $9(6-11)$ & $9(5-12)$ & $0.89^{c}$ & $9(6-11)$ \\
\hline $\begin{array}{l}\text { Non-respiratory co-morbidity was based on simp } \\
\text { disease, stroke, hypertension, Parkinson's diseas } \\
\text { Abbreviations: ATS, American Thoracic Society; B } \\
\text { Medical Research Council dyspnoea scale; MMSE } \\
\text { a } P \text { based on } t \text {-test for independent samples. } \\
\text { DP } P \text { based on Pearson } X^{2} \text { test. } \\
\text { C } P \text { based on Mann-Whitney U-test. }\end{array}$ & $\begin{array}{l}\text { lass index; COPD, } \\
\text { tal state examinati }\end{array}$ & $\begin{array}{l}\text { e, myocardial infarc } \\
\text { d cancer. } \\
\text { tructive pulmonary } \\
5,15 \text {-item Geriatric }\end{array}$ & $\begin{array}{l}\text { tes, atrial } \\
\mathrm{R} \text {, interqu } \\
\text { Scale; } \mathrm{PI}\end{array}$ & $\begin{array}{l}\text {, peripheral arterial } \\
\text { e; mMRC, modified } \\
\text { I performance test. }\end{array}$ \\
\hline
\end{tabular}

marker for adverse health outcomes in older adults can be assessed in spirograms in which plateau of $>6 \mathrm{~s}$ has not been reached (spirometry quality levels ATS 1-3 are usable for this purpose and were achieved by $96 \%$ of participants in the BELFRAIL and $80 \%$ of participants in the CRYSTAL study). ${ }^{4-8}$

Almost all the previous studies in older adults have reported a significant association between cognitive impairment (based on MMSE scores) and poor-quality spirometry, yet the definitions of cognitive impairment and quality spirometry differ between studies and most of their populations were inpatient or ambulatory patients with geriatric or respiratory problems. ${ }^{15-18,25,26,35,36}$ Only one previous study with a small number of independent participants attending a community centre has reported no association between poor-quality spirometry and MMSE scores, although it found an association with one of two other cognitive function tests that measure executive function to perform simple-directed tasks. ${ }^{24}$ In our study, cognitive impairment based on MMSE $\leqslant 24$ was not associated with poor-quality spirometry after adjustment for age, sex, BMI, level of education (BELFRAIL cohort only), physical functioning, affective status and co-morbidity. In the light of our findings and the fact that previous studies have focused on respiratory or geriatrics in/outpatients, it remains an issue for further research whether cognitive impairment (based on MMSE scores) is an independent predictor for poor-quality spirometry in community-dwelling older adults.

In the BELFRAIL cohort, asthma/COPD diagnosis halved the odds for poor-quality spirometry, probably because of previous 
Table 4. Multivariable logistic regression analysis of the association between MMSE score and poor spirometry quality in the CRYSTAL study

\begin{tabular}{|c|c|c|c|c|}
\hline Variables & Unadjusted & Model 1 & Model 2 & Model 3 \\
\hline Age & & $1.01(0.98-1.04)$ & $1.01(0.98-1.04)$ & $1.01(0.98-1.04)$ \\
\hline BMI & & $0.98(0.95-1.02)$ & $0.98(0.95-1.02)$ & $0.98(0.95-1.02)$ \\
\hline Barthel Index (<95) & & & $0.63(0.41-0.99)^{*}$ & $0.65(0.41-1.02)$ \\
\hline Grip strength (lowest gender-specific quartile) & & & $1.11(0.67-1.82)$ & $1.11(0.67-1.83)$ \\
\hline PPT (lowest gender-specific quartile) & & & $1.15(0.77-1.71)$ & $1.15(0.77-1.72)$ \\
\hline COPD/asthma & & & & $1.01(0.68-1.49)$ \\
\hline \multicolumn{5}{|c|}{$\begin{array}{l}\text { Multimorbidity was based on simple disease count of coronary heart disease, myocardial infarction, diabetes, atrial fibrillation, peripheral arterial disease, } \\
\text { stroke, hypertension, Parkinson's disease, arthritis or osteoarthritis, fractures and cancer. } \\
\text { Abbreviations: BMI, body mass index; COPD, chronic obstructive pulmonary disease; GDS-15, 15-item Geriatric Depression Scale; MMSE, mini-mental state } \\
\text { examination; PPT, physical performance test. } \\
{ }^{*} P<0.05 \text {. }\end{array}$} \\
\hline
\end{tabular}

'learning' experience with spirometry in those with asthma/COPD. Although female sex has been previously found to be a predictor of good-quality spirometry, ${ }^{14}$ in the BELFRAIL cohort we found that male sex almost halved the odds for poor-quality spirometry. This may be explained by the significantly higher prevalence of COPD/asthma in men in this cohort.

Strengths and limitations of this study

One of the limitations of this study is the exclusion criteria for participants of the BELFRAIL study (dementia or severe cognitive impairment or being in palliative or emergency care), but similar exclusion criteria have been applied in other previous studies on this topic. ${ }^{15,18,24}$ In the CRYSTAL study, it has not been possible to identify the clinical research assistants for each spirometry to analyse the effect of the variability of four different operators on the spirometry quality. Besides the participants' characteristics, the operator's interpersonal skills to instruct, engage and support/coach the patient through the spirometry manoeuver are crucial in achieving quality spirometry. ${ }^{14,37}$ There were also incomplete data on the education level in the CRYSTAL study to correct for its influence in multivariable analysis. The tests used to assess mental and physical functioning in both the studies are designed for screening purposes and may have under/overestimated the level of physical or mental impairment.

One of the strengths of this study is that it reports from two large heterogeneous cohorts of community-dwelling older adults in two countries such as Belgium and Russia with different sociodemographic and epidemiological contexts. ${ }^{21,22}$ Both study protocols included a standardised comprehensive geriatric assessment of the participants. Rigorous quality control of spirometry performance and interpretation based on the ATS/ ERS quality criteria were followed. Statistical multivariable analysis included most of the key factors previously reported as determinants of the spirometry quality in older adults.

Implications for future research, policy and practice

Further studies are needed on cognitive impairment as a predictor of poor-quality spirometry in community-dwelling older adults. Spirometry should be used more frequently in older adults in primary care without prejudice on age and mental and/or physical functioning, as it is a valuable tool not only for the diagnosis and management of respiratory diseases, but also for assessing overall health and risk for adverse outcomes in this worldwide growing age group.

\section{Conclusions}

In community-dwelling older adults, including those over 80 years old, impaired cognition measured by the MMSE may not be an independent predictor of poor-quality spirometry. Further research is needed in this area, and spirometry should be used more often in older adults in primary care.

\section{ACKNOWLEDGEMENTS}

The BELFRAIL study was made possible by the participating general practitioners who included their patients. The authors thank Dr Etienne Baijot (Beauraing), Dr Pierre Leclercq (Pondrôme), Dr Baudouin Demblon (Wellin), Dr Daniel Simon (Rochefort), Dr Daniel Vanthuyne (Celles), Dr Yvan Mouton (Godinne), Dr Louis-Philippe Docquier (Maffe), Dr Tanguy Dethier (Ciney), Dr Patricia Eeckeleers (Leignon), Dr Jean-Paul Decaux (Dinant), Dr Christian Fery (Dinant), Dr Pascale Pierret (Heure), Dr Paul-Emile Blondeau (Beauraing), Dr Baudry Gubin (Beauraing), Dr Jacques Guisset (Wellin), Dr Quentin Gillet (Mohiville), Dr Arlette Germay (Houyet), Dr Jan Craenen (Hoeilaart), Dr Luc Meeus (Hoeilaart), Dr Herman Docx (Hoeilaart), Dr Ann Van Damme (Hoeilaart), Dr Sofie Dedeurwaerdere (Hoeilaart), Dr Bert Vaes (Hoeilaart), Dr Stein Bergiers (Hoeilaart), Dr Bernard Deman (Hoeilaart), Dr Edmond Charlier (Overijse), Dr Serge Tollet (Overijse), Dr Eddy Van Keerberghen (Overijse), Dr Etienne Smets (Overijse), Dr Yves Van Exem (Overijse), Dr Lutgart Deridder (Overijse), Dr Jan Degryse (Oudergem), Dr Katrien Van Roy (Oudergem), Dr Veerle Goossens (Tervuren), Dr Herman Willems (Overijse) and Dr Marleen Moriau (Bosvoorde). The CRYSTAL study authors express their appreciation to the staff of polyclinic of Kolping in St Petersburg, Russia: head of the polyclinic, Tatyana Isaeva, chief nurses Irina Yakovleva and Irina Dobritsa for their input to the organisation and management of the study, as well as to the team of 14 nurses for their invaluable contribution to the performance of the research.

\section{CONTRIBUTIONS}

JD and BV designed the BELFRAIL study. EF and JD designed the CRYSTAL study. ET analysed the BELFRAIL data and drafted the first version of the manuscript. DZ and JD assessed the CRYSTAL's spirometry quality. DZ analysed the CRYSTAL data. EA and JD assessed the BELFRAIL's spirometry quality. All the authors have read and approved the final manuscript.

\section{COMPETING INTERESTS}

The authors declare no conflict of interest.

\section{FUNDING}

The CRYSTAL study was supported by a fund of the President of the Russian Federation (Grant 192-RP). The BELFRAIL study (B40320084685) was supported by an unconditional grant from Fondation Louvain, Brussels, Belgium. Fondation Louvain is the support unit of Université Catholique de Louvain and is charged with developing the educational and research projects of the university by collecting gifts from corporations, foundations and alumni. 


\section{REFERENCES}

1 Mannino DM, Buist AS. Global burden of COPD: risk factors, prevalence, and future trends. Lancet 2007; 370: 765-773.

2 Global Initiative for Chronic Obstructive Lung Disease (GOLD). Global Strategy for the Diagnosis, Management and Prevention of COPD 2015. Available from http://www.goldcopd.org/.

3 Global Initiative for Asthma (GINA). Global Strategy for Asthma Management and Prevention 2015. Available from: http://www.ginasthma.org/.

4 Lange P. Spirometric findings as predictors of survival. Thorax 2011; 66: 1-2.

5 Schunemann HJ, Dorn J, Grant BJ, Winkelstein W Jr, Trevisan M. Pulmonary function is a long-term predictor of mortality in the general population: 29-year follow-up of the Buffalo Health Study. Chest 2000; 118: 656-664.

6 Singh-Manoux A, Dugravot A, Kauffmann F, Elbaz A, Ankri J, Nabi H et al. Association of lung function with physical, mental and cognitive function in early old age. Age (Dordr) 2011; 33: 385-392.

7 Vaz Fragoso CA, Enright PL, McAvay G, Van Ness PH, Gill TM. Frailty and respiratory impairment in older persons. Am J Med 2012; 125: 79-86.

8 Turkeshi E, Vaes B, Andreeva E, Mathei C, Adriaense W, vanPottelbergh G et al. Shortterm prognostic value of forced expiratory volume in 1 second divided by height cubed in a prospective cohort of people 80 years and older. BMC Geriatr 2015; 15: 15.

9 Arne M, Lisspers K, Ställberg B, Boman G, Hedenström H, Janson C et al. How often is diagnosis of COPD confirmed with spirometry? Respir Med 2010; 104: 550-556.

10 Lamprecht B, Mahringer A, Soriano JB, Kaiser B, Buist AS, Studnicka M et al. Is spirometry properly used to diagnose COPD? Results from the BOLD study in Salzburg, Austria: a population-based analytical study. Prim Care Respir J 2013; 22 195-200.

11 Han MK, Kim MG, Mardon R, Renner P, Sullivan S, Diette GB et al. Spirometry utilization for COPD: how do we measure up? Chest 2007; 132: 403-409.

12 Derom E, van Weel C, Liistro G, Buffels J, Schermer T, Lammers E et al. Primary care spirometry. Eur Respir J 2008; 31: 197-203.

13 Miller MR, Hankinson J, Brusasco V, Burgos F, Casaburi R, Coates A et al. Standardisation of spirometry. Eur Respir J 2005; 26: 319-338.

14 Enright $\mathrm{P}$, Lehmann S. Spirometry in old age: feasibility and interpretation. In: Bellia V, Incalzi RA (eds). European Respiratory Monograph 43: Respiratory Diseases in the Elderly. vol. 43 European Respiratory Society Journals: Sheffield, UK 2009; 25-34.

15 Bellia V, Pistelli R, Catalano F, Antonelli-Incalzi R, Grassi V, Melillo G et al. Quality control of spirometry in the elderly. The SA.R.A. study. SAlute Respiration nelI'Anziano = Respiratory Health in the Elderly. Am J Respir Crit Care Med 2000; 161 1094-1100

16 Pezzoli L, Giardini G, Consonni S, Dallera I, Bilotta C, Ferrario G et al. Quality of spirometric performance in older people. Age Ageing 2003; 32: 43-46.

17 De Filippi F, Tana F, Vanzati S, Balzarini B, Galetti G. Study of respiratory function in the elderly with different nutritional and cognitive status and functional ability assessed by plethysmographic and spirometric parameters. Arch Gerontol Geriatr 2003; 37: 33-43.

18 Allen S, Yeung $P$, Janczewski $M$, Siddique N. Predicting inadequate spirometry technique and the use of FEV1/FEV3 as an alternative to FEV1/FVC for patients with mild cognitive impairment. Clin Respir J 2008; 2: 208-213.

19 Allen SC, Yeung P. Inability to draw intersecting pentagons as a predictor of unsatisfactory spirometry technique in elderly hospital inpatients. Age Ageing 2006; 35: 304-306.

20 Czajkowska-Malinowska M, Tomalak W, Radlinski J. Quality of spirometry in the elderly. Pneumonol Alergol Pol 2013; 81: 511-517.
21 Vaes B, Pasquet A, Wallemacq P, Rezzoug N, Mekouar H, Olivier PA et al. The BELFRAIL (BFC80+) study: a population-based prospective cohort study of the very elderly in Belgium. BMC Geriatr 2010; 10: 39.

22 Gurina NA, Frolova EV, Degryse JM. A roadmap of aging in Russia: the prevalence of frailty in community-dwelling older adults in the St. Petersburg District-the "Crystal" study. J Am Geriatr Soc 2011; 59: 980-988.

23 Degryse J, Buffels J, Van Dijck Y, Decramer M, Nemery B. Accuracy of office spirometry performed by trained primary-care physicians using the MIR Spirobank hand-held spirometer. Respiration 2012; 83: 543-552.

24 Sherman CB, Kern D, Richardson ER, Hubert M, Fogel BS. Cognitive function and spirometry performance in the elderly. Am Rev Respir Dis 1993; 148: 123-126.

25 Carvalhaes-Neto $\mathrm{N}$, Lorino $\mathrm{H}$, Gallinari C, Escolano $\mathrm{S}$, Mallet $\mathrm{A}$, Zerah $\mathrm{F}$ et al. Cognitive function and assessment of lung function in the elderly. Am J Respir Crit Care Med 1995; 152: 1611-1615.

26 Lehmann S, Vollset SE, Nygaard HA, Gulsvik A. Factors determining performance of bronchodilator reversibility tests in middle-aged and elderly. Respir Med 2004; 98: 1071-1079.

27 Haynes JM. Pulmonary function test quality in the elderly: a comparison with younger adults. Respir Care 2014; 59: 16-21.

28 American Thoracic Society. Standardization of spirometry,1994 update. Am J Respir Crit Care Med 1995; 152: 1107-1136.

29 Melbye $\mathrm{H}$, Medbo A, Crockett A. The FEV1/FEV6 ratio is a good substitute for the FEV1/FVC ratio in the elderly. Prim Care Respir J 2006; 15: 294-298.

30 Bellia V, Sorino C, Catalano F, Augugliaro G, Scichilone N, Pistelli R et al. Validation of FEV6 in the elderly: correlates of performance and repeatability. Thorax 2008 63: 60-66.

31 Vandevoorde J, Verbanck S, Schuermans D, Kartounian J, Vincken W. FEV1/FEV6 and FEV6 as an alternative for FEV1/FVC and FVC in the spirometric detection of airway obstruction and restriction. Chest 2005; 127: 1560-1564.

32 Bhatt SP, Kim YI, Wells JM, Bailey WC, Ramsdell JW, Foreman MG et al. FEV(1)/FEV (6) to diagnose airflow obstruction. Comparisons with computed tomography and morbidity indices. Ann Am Thorac Soc 2014; 11: 335-341.

33 Enright PL. Are six seconds long enough? Prim Care Respir J 2006; 15: 268-270.

34 loachimescu OC, Venkateshiah SB, Kavuru MS, McCarthy K, Stoller JK. Estimating FVC from FEV2 and FEV3: assessment of a surrogate spirometric parameter. Chest 2005; 128: 1274-1281.

35 Allen SC, Baxter M. A comparison of four tests of cognition as predictors of inability to perform spirometry in old age. Age Ageing 2009; 38: 537-541.

36 Allen SC, Charlton C, Backen W, Warwick-Sanders M, Yeung P. Performing slow vital capacity in older people with and without cognitive impairment-is it useful? Age Ageing 2010; 39: 588-591.

37 Enright PL, Skloot GS, Cox-Ganser JM, Udasin IG, Herbert R. Quality of spirometry performed by 13,599 participants in the World Trade Center Worker and Volun teer Medical Screening Program. Respir Care 2010; 55: 303-309.

(c) (i)

This work is licensed under a Creative Commons Attribution 4.0 International License. The images or other third party material in this article are included in the article's Creative Commons license, unless indicated otherwise in the credit line; if the material is not included under the Creative Commons license, users will need to obtain permission from the license holder to reproduce the material. To view a copy of this license, visit http://creativecommons.org/licenses/ by/4.0/ 